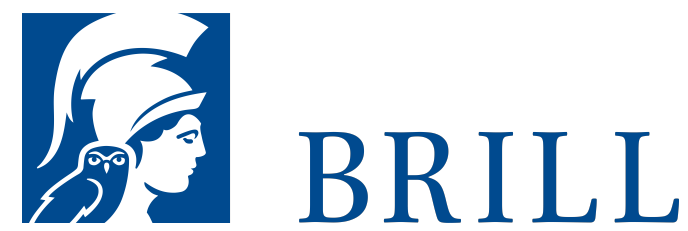

\title{
Schauspiele des Halbversteckten
}

Eine Bildgeschichte des gemalten Vorhangs

Author: Claudia Blümle

Im Akt der Enthüllung lässt ein beiseite geschobener Vorhang etwas zum Vorschein kommen, das zuvor verborgen war, und löst dadurch nicht nur das Interesse aus, dieses weiter zu ergründen, sondern lenkt auch unser Sehen. Dabei wird ersichtlich, mit welchen Mitteln ein Betrachter verführt wird, sich ein Bild anzusehen und wann welche Praktiken bestimmen, ob etwas in einem Bild zu sehen gegeben wird oder nicht gezeigt werden darf. Das vorliegende Buch fragt danach, auf welche Weise ein Vorhang im oder vor dem Bild die Begegnung mit dem Bild provoziert. Denn im Gegensatz zu einem distanzierten Sehen fordern die Vorhänge in den hier behandelten Kunstwerken vom 15. bis zum 19. Jahrhundert (u.a. Vermeer, Tizian, Velázquez, Manet, Cézanne) den Betrachter dazu auf, sich auf das im Bild Gezeigte einzulassen. Es ist ein Sehen, das zwischen dem Davor-Stehen und Sich-im-BildBewegen zu pendeln beginnt. Ein Bild besteht somit weniger darin, Bedeutungsträger zu sein, sondern vielmehr darin, ein Zusammenspiel mit dem Betrachter und ein Sehen im Bild zu entfachen, dessen Reiz im Schauspiel des Halbversteckten liegt.

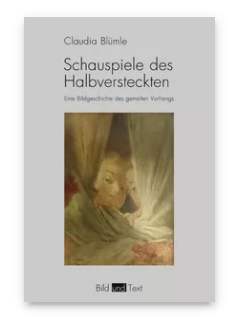

Published: 30 Jul 2023

Subjects: Art History, Art History

Publisher: Brill | Fink

Series:

Bild und Text

E-Book (PDF)

ISBN: 978-38467-6287-5 Paperback ISBN: 978-37705-6287-9 
Claudia Blümle ist Professorin für Geschichte und Theorie der Form am Institut für Kunst- und Bildgeschichte der HumboldtUniversität zu Berlin und am Excellenzcluster „Bild Wissen Gestaltung. Ein interdisziplinäres Labor". Ihre Forschungsschwerpunkte liegen sowohl in der Ästhetik, Kunstphilosophie und Bildtheorie, als auch im Bereich Bildtechniken und Wissenschaft vom 19. bis 21. Jahrhundert.

Please send your order to: Brockhaus/Commission Tel: +49(o)71 541327 9216 | E-Mail: brill@ $\underline{\text { brocom.de }}$

For questions please contact: Brill Deutschland GmbH Wollmarktstraße 115 | 33098 Paderborn | Germany Tel: +49 (o)5251 69975 o | E-Mail: sales@ $\underline{\text { brill.com. }}$ 